\title{
Application of rock mass classification systems as a tool for rock mass strength determination
}

\author{
A Moser Montanuniversitaet Leoben, Austria \\ H Wagner Montanuniversitaet Leoben, Austria \\ S Schinagl Montanuniversitaet Leoben, Austria
}

\begin{abstract}
The determination of the in situ rock mass strength can be found among the most difficult and challenging investigations in underground mining. The focus of a research project carried out in an underground magnesite mine was the assessment of the rock mass strength using the conventional approaches of rock mass classification, namely Rock Quality Designation (RQD) value after Deere and Deere (1988), Geological Strength Index (GSI) after Hoek et al. (2002), Rock Mass Rating (RMR) after Bieniawski (1989), Q-system after Barton (1990) and Mining Rock Mass Rating (MRMR) after Laubscher (1990) and information on laboratory rock strength. These methods were applied in an underground drift in the vicinity of a stoping panel in order to determine the rock mass strength as well as the influence of the approaching mining activities on the rock mass conditions. Supplementary, core drilling was conducted to provide samples for rock strength determination as well as for the observation of the rock mass conditions using a borehole camera. Based on the results of the rock mass classification systems and uniaxial rock strength tests, the rock mass strength was determined using different approaches. Further on the rock mass strength results were compared to the estimated in situ state of stress, calculated by the weight of the overlying rock strata, assuming a hydrostatic state of stress and physical conditions of the drift. The results from the rock mass strength determination were in the range of $15-450 \%$ of the estimated in situ pre-mining state of stress. The results of borehole observations and RQD measurements show considerable variations in rock conditions in the immediate vicinity of drift ranging from extensive fracturing to fairly competent rock. However, with further distance from the drift, the condition of the rock mass changes to that of a massive and undisturbed rock mass.
\end{abstract}

This highlights the difficulties of arriving at realistic rock mass strength values for the deep section of the magnesite mine. The aspects concerning this problem are discussed in detail.

Keywords: rock fracturing, rock mass classification, rock mass strength, deep mining

\section{Introduction}

As mining activities continue to become deeper and deeper, rock stress problems come to the fore and require special attention as they influence the overall stability of the mine, might cause safety hazards and can impact on mine operations, productivity and costs. In order to assess the stability of a mining system, the governing stresses and the strength of the rock mass have to be considered and compared. When the in situ state of stress exceeds the strength of the rock mass, failure will occur, which is predominantly the case in the immediate vicinity of underground excavations. The assessment of the strength of the rock mass is one of the most challenging issues in rock mechanics as far as the design of mining layouts are concerned that are safe but at the same time maximise mineral extraction. As the direct determination of the rock mass strength in situ is for all practical purposes difficult, if not impossible, indirect methods of derivation of the rock mass properties have been developed. 
In the most simple terms the problem consists of three parts, namely:

- Quantification of strength and deformation behaviour of the rock types making up the rock mass in the area of concern.

- Mechanistically-appropriate description and quantification of the effects of discontinuities on rock mass behaviour, i.e. number of discontinuity systems, spacing and orientation of discontinuities, properties of discontinuity interfaces.

- Development of algorithms to determine and quantify rock mass properties which take into account the effects of rock properties and the effect of discontinuities.

Numerous methods have been developed to determine rock mass properties and in particular rock mass strength. These are based on rock sample testing in the laboratory, rock mass classification systems (Bieniawski 1989; Laubscher 1990; Barton 1990; Hoek et al. 2002), numerical modeling, back-analysis of rock failures in isolated mining excavations (Edelbro 2003; Martin et al. 1999) and statistical analysis of mining conditions (Salamon \& Munro 1967; Wiseman 1979).

Among these methods, the most commonly used technically and economically feasible methods, are empirical or semi-empirical approaches like the RQD value (Deere \& Deere 1988), the RMR value after Bieniawski (1989), the MRMR value after Laubscher (1990), the Q-system after Barton (1990) and the GSI after Hoek et al. (2002). These approaches are based on the visual observation of the excavation sidewalls and roof strata as well as on information from borehole logging or core drilling and laboratory testing of rock properties. Based on the results of these investigations, different approaches to determine the rock mass strength were developed (Ramamurthy 1985; Hoek et al. 2002; Trueman 1988; Laubscher 1990); Barton 2002).

The aim of this paper is to present the application of the mentioned rock mass strength determination in an Austrian underground mine and to highlight the difficulties and uncertainties encountered in applying these methods for certain mining situations.

\section{Rock mass investigation}

The rock mass investigation was conducted in an Austrian underground magnesite mine in order to assess the strength of the rock mass in the deepest part of the mine. The concerned deposit is a uniform sparry magnesite formation that has undergone different tectonic activities with the result that in some areas of the deposit shear zones have developed. The mining section covered by this investigation employs a system of large stopes separated by slender pillars. Immediately after completing a stope the excavation is filled with cemented backfill. The depth of mining approaches $1,000 \mathrm{~m}$, the individual stopes are $21 \mathrm{~m}$ high, $6 \mathrm{~m}$ wide and up to $80 \mathrm{~m}$ long. The stopes are separated by $7 \mathrm{~m}$ wide pillars. Only one stope is mined in a section at any time. After the stope has been backfilled the adjacent stope is excavated. In Figure 1 the stoping area is shown, including markings for the selected areas, namely stope 600E, stope 600F, stope 600G (at time of paper preparation under development) and drift $600 \mathrm{H}$.

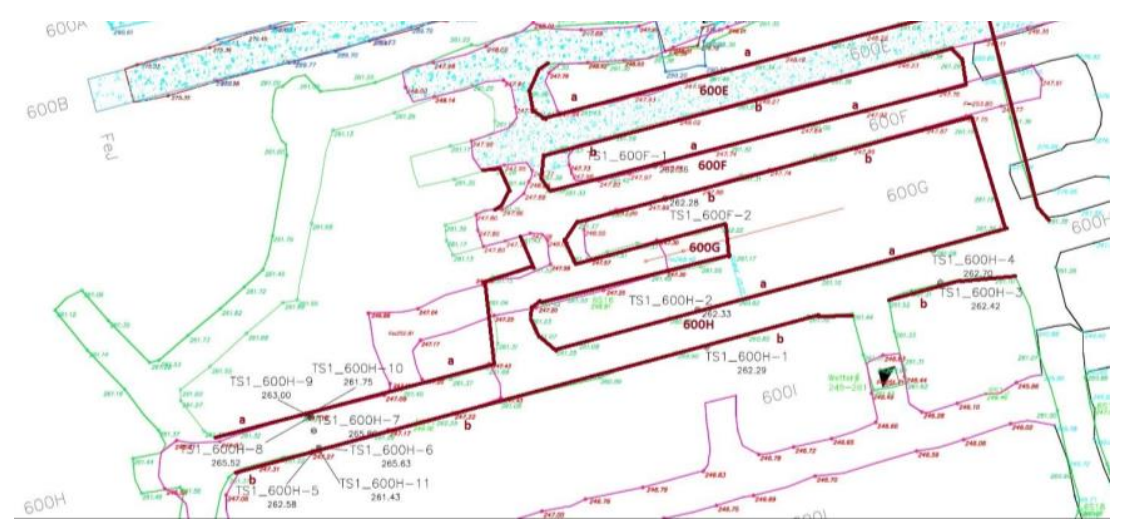

Figure 1 Mining panel in the investigated underground mine 
For the assessment of the rock mass properties the following rock mass classification systems were applied (Siefert 2009):

- RQD value after Deere \& Deere (1988) (method using only one parameter).

- RMR after Bieniawski (1989) (sum of single parameters).

- MRMR after Laubscher (1990) (sum of single parameters).

- Q-System after Barton (1990) (product of different factors).

- GSI after Hoek \& Brown (2002) (on the basis of a chart).

The above mentioned systems were chosen among a multitude of rock mass classification systems based on their suitability as well as the common use of these systems in underground mining application. Each of the presented rock mass classification systems was developed for certain mining or tunnelling conditions resulting in a rating of the rock mass. Some of the methods also provide suggestions for suitable support systems. A detailed description of the rock mass classification methods is left out as the application of these methods is in the focus of the presented work rather than the theory behind the systems.

Table 1 summarises the input parameters for the applied rock mass classification systems. Under the term 'rock strength' the authors understand the strength of intact rock as determined in the laboratory in contrast to the 'rock mass strength', which is the in situ strength of the rock. Taking a look in detail at the input parameters, similarities can be observed between the RMR and the MRMR system, using both the same input parameters. The main difference between these two systems lies in the adjustments that are undertaken in the MRMR system, which is the only rock mass classification system considering the influence of mining activities. The GSI for example does not consider the rock strength and is strictly speaking a discontinuity assessment parameter which takes into consideration the overall structure of rock mass and the properties of the discontinuities. The rock strength is considered separately when calculating the rock mass strength.

Table 1 Parameters considered in the applied rock mass classification systems (after Zhang 2010)

\begin{tabular}{|c|c|c|c|c|}
\hline $\begin{array}{l}\text { Classification } \\
\text { system }\end{array}$ & RMR & MRMR & $\mathbf{Q}$ & GSI \\
\hline \multirow[t]{6}{*}{ Parameters } & $\begin{array}{l}\text { Uniaxial } \\
\text { compressive } \\
\text { strength (UCS) }\end{array}$ & UCS & & $\begin{array}{l}\text { Discontinuity } \\
\text { conditions }\end{array}$ \\
\hline & RQD & RQD & RQD & $\begin{array}{l}\text { Structure/interlocking } \\
\text { of rock blocks }\end{array}$ \\
\hline & Joint spacing & Joint spacing & Joint roughness $\mathrm{J}_{\mathrm{r}}$ & \\
\hline & $\begin{array}{l}\text { Joint } \\
\text { condition }\end{array}$ & $\begin{array}{l}\text { Joint } \\
\text { condition }\end{array}$ & Joint alteration $\mathrm{J}_{\mathrm{a}}$ & \\
\hline & $\begin{array}{l}\text { Groundwater } \\
\text { condition }\end{array}$ & $\begin{array}{l}\text { Groundwater } \\
\text { condition }\end{array}$ & Joint water reduction factor $J_{w}$ & \\
\hline & & & Stress reduction factor (SRF) & \\
\hline $\begin{array}{l}\text { Adjustment } \\
\text { parameters }\end{array}$ & $\begin{array}{l}\text { Joint } \\
\text { orientation }\end{array}$ & $\begin{array}{l}\text { Joint } \\
\text { orientation, } \\
\text { blasting and } \\
\text { weathering }\end{array}$ & & \\
\hline
\end{tabular}


The Rock Quality Designation value (RQD) was developed to describe the degree of fracturing of the rock mass. On the one hand the parameter can be used itself as direct estimation of the rock mass condition as well as an input parameter for several rock mass classification systems (e.g. RMR, MRMR, Q-system) (Siefert 2009).

The RQD is a modified percentage of the drill core recovery, where the length of all intact core pieces, larger than $100 \mathrm{~mm}$ is summed up and divided by the length of the investigated section.

By default the length of the cores is measured along the centre line of the core. Fractures that are caused by the drilling process should not be considered during the RQD determination (Deere \& Deere 1988).

\subsection{Critical comments concerning rock mass classification systems}

When using the different rock mass classification systems, one has to be aware of several simplifications or characteristics of the individual systems, which will be highlighted in the following.

Regarding the rock mass assessment approaches in detail, the overriding importance of discontinuities can be observed. Depending on the classification system, up to $70 \%$ of the score is discontinuity based, whereas other important parameters are not considered. The systems also show a relative unimportance of the rock strength. The rock strength is not directly considered in the Q-system (the rock strength is covered indirectly in the stress factor) and in the GSI system. In the RMR system, the rock strength represents a maximum value of $15 \%$ of the total rating, whereas in the MRMR system it accounts for maximum $20 \%$ of the total rating. This highlights the low importance of rock strength in the classification methods. Concerning rock strength, it has to be stated that for all classification systems except the MRMR system an overall rock strength value is used. Only the MRMR value takes the intact rock strength (IRS) in MPa as an input parameter which is not the uniaxial compressive strength of the rock, but a value which considers different beddings in the rock mass structure. However, calculating the IRS is only possible for sedimentary deposits, as the determination of the IRS is based on different strength values of different rock layers. Taking a look at the classification systems, the difference in calculation of the ratings has to be discussed as well. In case of additive systems like the RMR system or the MRMR system, the effect of an individual parameter is rather small, whereas in case of Barton's Q-system the change in one single parameter can have a major effect on the overall rating, as it is calculated by multiplying the individual parameters.

The GSI system is a very simple and quick classification system. For typical geological situations charts have been developed which allow the determination of the geological index value, GSI. The charts are based on an assessment of the overall rock mass structure, but the question arises how this overall structure can be assessed and quantified. While this is relatively straight forward in case of sedimentary deposits (sandstone, limestone, etc.) or in case of massive unjointed deposits, great difficulties are encountered in tectonically stressed rock including multiple fault and shear zones or complex joint systems such as found in the investigated mine. Some of the difficulties mentioned can be overcome by defining block sizes and block volumes (Cai et al. 2004). Blasting damage, resulting from high energy input at the excavation sidewalls and stress induced fractures in the immediate vicinity of the excavation can lead to unjustified low GSI assessments. Therefore the question arises if and how the GSI system should be applied in such situations. This point will be discussed in some detail later on. For GSI values under 25 the method should not be used according to several authors (Siefert 2009; Brady \& Brown 2006; Marinos \& Hoek 2000). Since the submission of the draft of this paper one of the reviewers brought to the attention of the authors a recent publication by Hoek et al. (2013) which deals with the difficulties outlined above. This will be considered in future analyses.

\subsection{Difficulties using conventional rock mass classification systems}

The input parameters for each classification system leave a certain margin for individual estimations of the person conducting the rock mass classification. This means that analyses of a particular mining area performed by two different persons can result in different ratings.

In addition, classification systems based on visual observation of rock wall conditions tend to be strongly biased towards a disturbed rock mass since the excavation sidewalls have been affected by blasting activities 
and mining-induced stress changes. Even though the attempt was made not to include induced fractures into the rock mass classification, the strained rock mass affects the overall impression and therefore the result of the rock mass evaluation. The situation is aggrevated by the fact that the input values can vary significantely over short distances. This raises the issue which value to use.

The RQD value as well as the UCS of the rock are important input-parameters for all applied systems except the GSI rating system. In deep mines determination of representative RQD values from drill cores is a difficult issue as the rock in the vicinity of the drifts from where the holes are drilled is adversely affected by drift development and stress changes. Figure 2 shows the variation of RQD values with distance from the drift wall. The RQD values for each drill core are one metre average values. The influence of distance from drift wall on RQD is clearly visible. The first two metres from the drift wall are characterised by low and variable RQD values. At greater distances the RQD values tend to be higher and more stable. For these reasons the first two metres of drill core have been excluded from the calculation of average RQD values used for rock mass classification. A comparison of RQD values from two parallel holes that were drilled two metres apart shows considerable differences in RQD values over such short distances, see drillhole E20 and drillhole E21 in pillar 600E. These examples highlight the difficulties encountered in performing rock mass assessments in tectonically stressed rock masses.

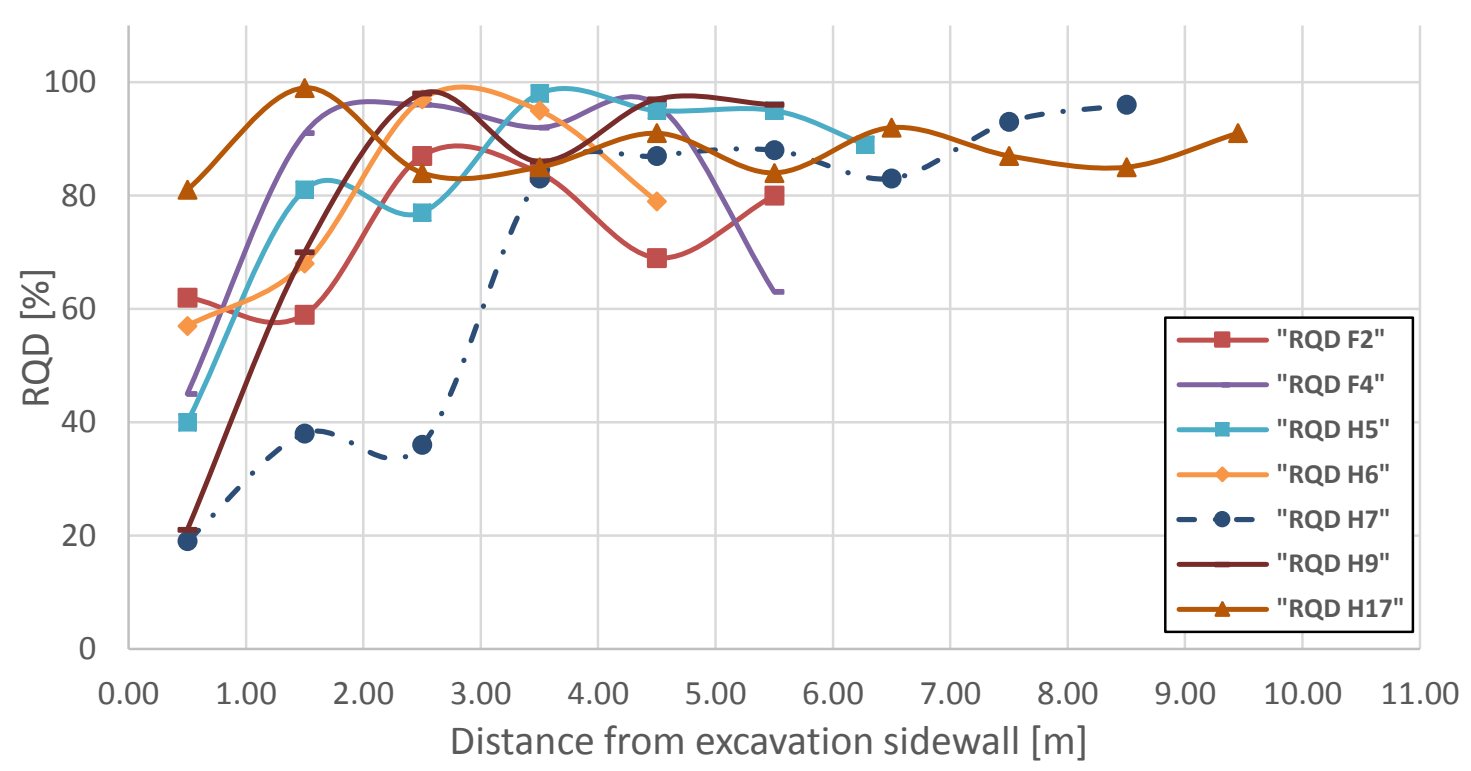

Figure 2 Effect of drift wall distance on RQD values (RQD values from drillholes stope pillars and in fault zones have been excluded)

As far as the strength of rock samples taken from a drill core is concerned it could be argued that the rock strength is higher in those portions of the drill core where high RQD values are observed as the rock is intact and not affected by geological fractures or by mining activities and stress changes. Conversely, drill core sections with low RQD values are either an indication for a rock mass which is geologically strongly disturbed or affected by high rock stresses and stress changes causing rock fractures. In this case it could be argued that the rock has been damaged and the core samples have many of micro fractures, leading to low rock strength as well. To test this hypothesis Figure 3 has been prepared which shows the relationship of RQD and rock strength. It should be noted that it was not possible to prepare a representative number of test specimen from low RQD portions of the drill cores. According to Figure 3 no correlation between the RQD value and the UCS of the rock could be found in the range of $60<R Q D<100$. The differences in strength values observed in this investigation are related to local rock conditions which in some instances were found to change over short distances. 


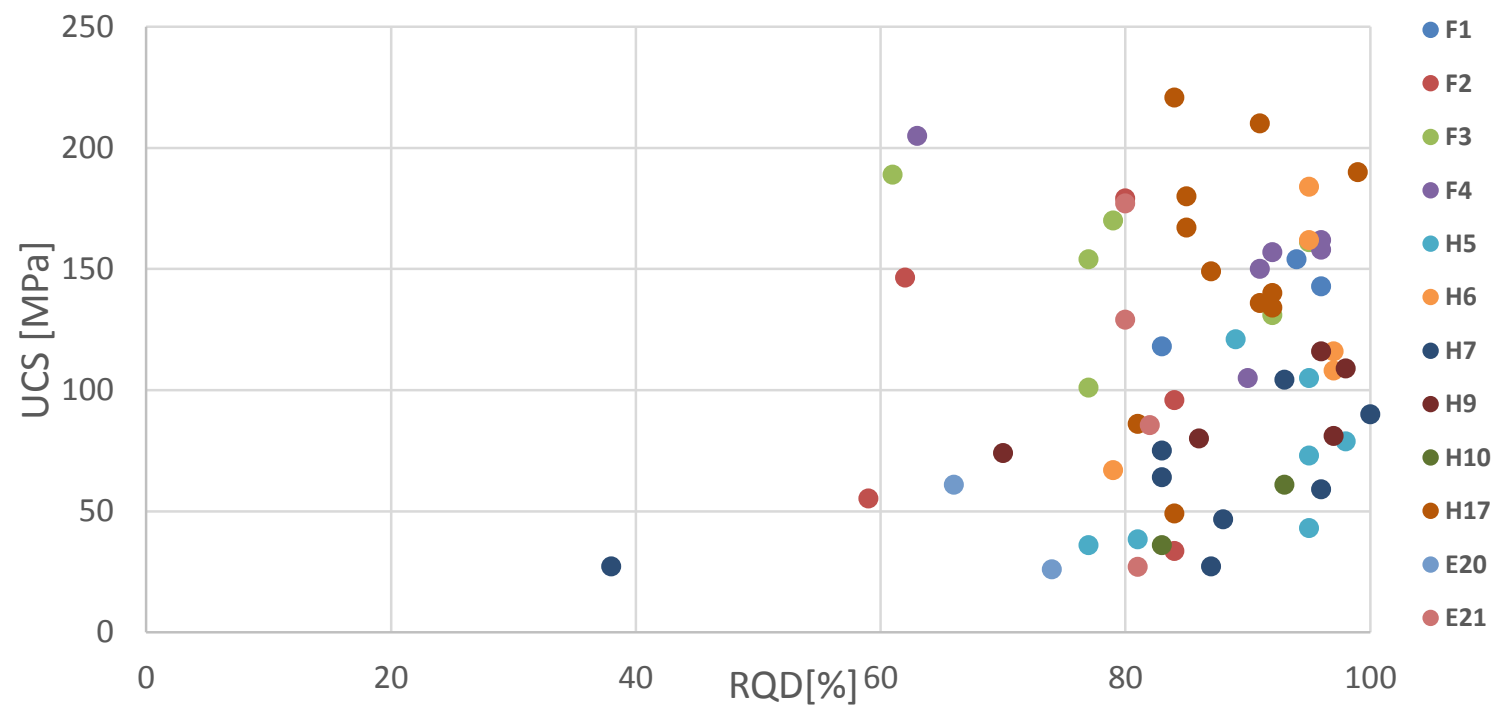

Figure 3 Relation between UCS and RQD value

Uniaxial compression test samples were prepared from the drill cores at metre intervals to determine possible influences of distance from drift wall on UCS. The results of the uniaxial compression tests are shown in Figure 4. Rock cores from stope pillars and fault zones have been excluded from this investigation. No distinct effect of distance from drift wall on UCS has been found. Considerable variations in compressive strength along individual holes and between holes have been observed. This again highlights the difficulty in arriving at representative strength values for rock mass strength determination.

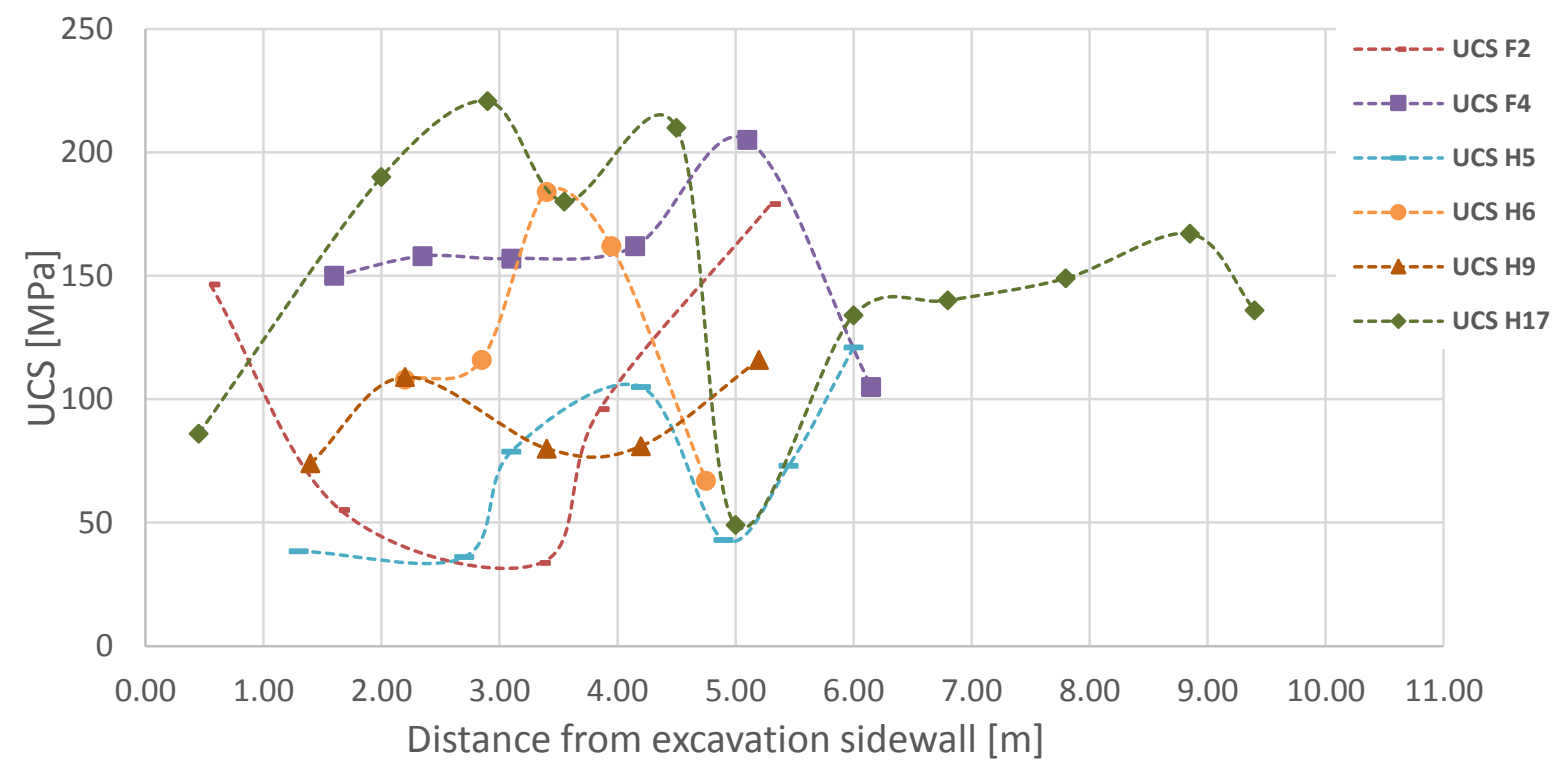

Figure 4 Variation of UCS over drillhole length

Table 2 summarises the uniaxial compressive strength values from drill cores around drifts. As can be seen from this tabulation the variation in average UCS values at different distances from the drift wall, with one exception (distance 1-2m) is moderate but the variation of UCS values between different drillholes at given distances from the drift wall can be quite large. 
Table 2 Mean value and standard deviation of UCS in chosen sections

\begin{tabular}{|c|c|c|c|c|c|c|c|c|c|c|}
\hline Section & $0-1 \mathrm{~m}$ & $1-2 \mathrm{~m}$ & $2-3 m$ & $3-4 \mathrm{~m}$ & $4-5 m$ & $5-6 m$ & $6-7 \mathrm{~m}$ & $7-8 \mathrm{~m}$ & $8-9 \mathrm{~m}$ & $9-10 \mathrm{~m}$ \\
\hline Number & 2 & 4 & 7 & 8 & 6 & 5 & 4 & 1 & 1 & 1 \\
\hline Mean value (MPa) & 116 & 79 & 134 & 121 & 111 & 124 & 125 & 149 & 167 & 136 \\
\hline Standard deviation (MPa) & 30 & 43 & 57 & 53 & 58 & 60 & 13 & & & \\
\hline
\end{tabular}

Regarding the UCS, it can be observed that over a length of $6 \mathrm{~m}$ in a distance of $1 \mathrm{~m}$ between the boreholes, variations of the UCS between 61 and $177 \mathrm{MPa}$ were observed. Taking a look at the abutment pillar $600 \mathrm{H}$, even more significant results can be obtained. Over a borehole length of $9.5 \mathrm{~m}, \mathrm{RQD}$ values/metre between 14 (first metre of the excavation surrounding) and $100(7.5-8.5 \mathrm{~m})$ were measured. Also the UCS of the rock varies between $27 \mathrm{MPa}$ (obtained at $5 \mathrm{~m}$ ) and $104 \mathrm{MPa}(7.5 \mathrm{~m}$ ) (Figures 5 and 6). These results clearly highlight the difficulty and limitations of applying classical rock mass classification systems for quantifying rock mass properties. One important finding is that in the case of deeper mines RQD and UCS values determined from drill cores within the fracture zone of mining excavations cannot provide a realistic assessment of rock mass properties.

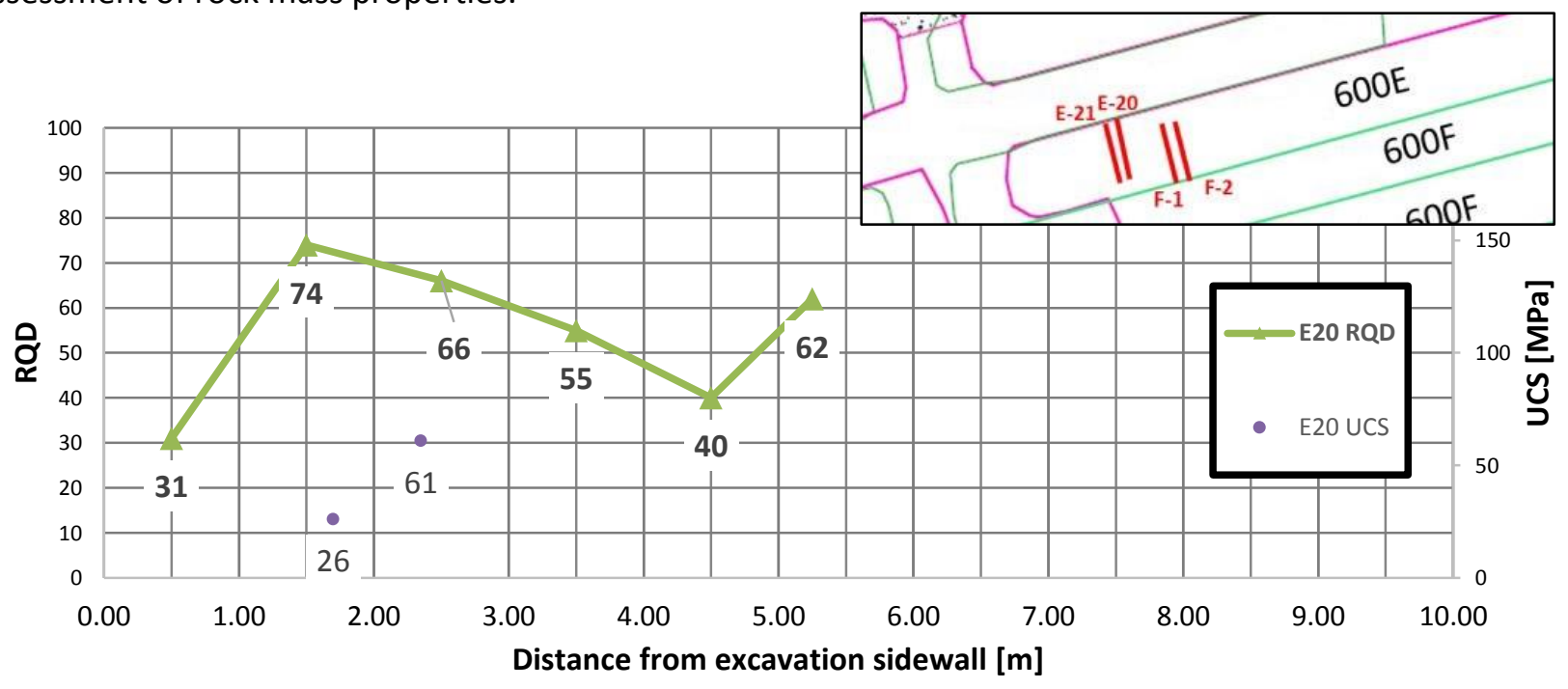

(a)

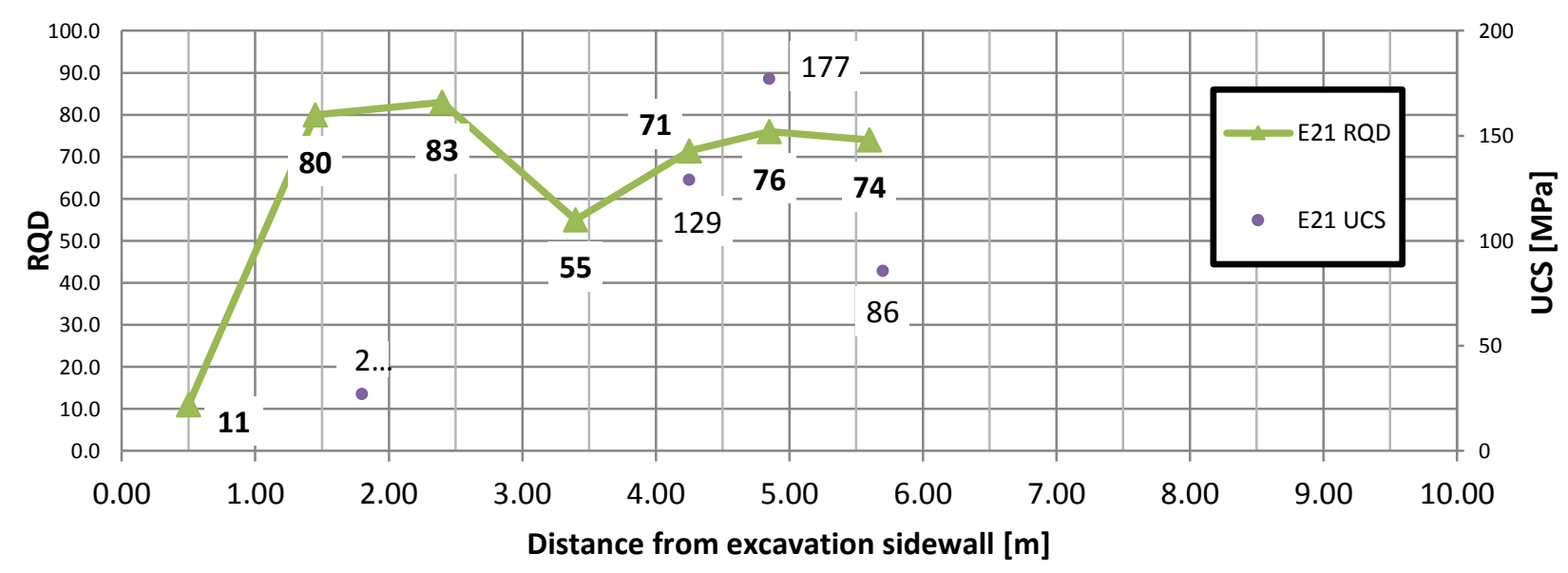

(b)

Figure 5 Variation of the RQD value and the UCS in pillar 600E; (a) drillhole E20; (b) drillhole E21) 


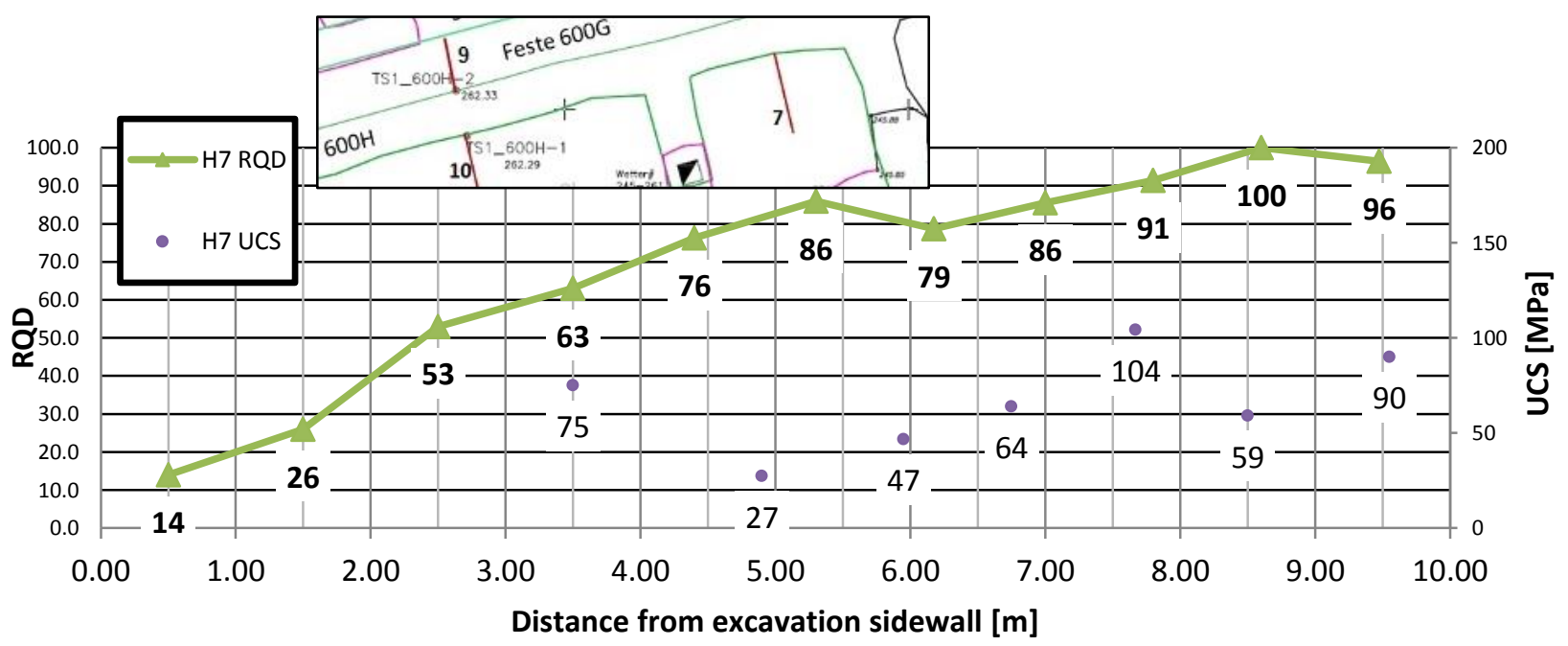

Figure 6 Variation of RQD value and UCS in abutment pillar $600 \mathrm{H}$

\subsection{Results from the application of the rock mass classification systems}

The presented rock mass classification systems were applied in the described underground mine. The top drifts of the stopes $600 \mathrm{E}$ and $600 \mathrm{~F}$ were documented before sill pillar extraction as well as the parallel drift to the mining panel $600 \mathrm{H}$. During the application of the rock mass classification systems the sidewalls of the drifts were roughly divided into 8-18 m long sections (according to local conditions) and documented separately for the different rock mass classification systems. When considering input parameters like joint spacing or opening of joints, an attempt was made to separate geological disturbances, joints and structures from mining induced fractures, i.e. blast fractures and stress fractures. The reason for the differentiation between geological and mining/stress-induced fractures is the fact that the latter are local features in the vicinity of the drives and not pertinent features of the rock mass. Therefore the influence of mining/stress-induced features on the overall stability of the rock mass is limited and should not be considered for the assessment of the regional rock mass strength.

A distinction between natural and induced fractures was made based on the following characteristics:

- Geometrical significance of features along a drift or excavation (e.g. related to the direction of drifting).

- No observable shear movement along features.

- No grinded material between fracture surfaces.

- No joint filling or covering.

- Rough fracture surfaces (e.g. indirect tension fractures).

- Fractures developing through grains.

Concerning the denomination of the sidewalls, the northern sidewalls in all drifts are called ' $a$ ' and the sidewalls in the south are called ' $b$ ' (Figure 1). Regarding drift $600 \mathrm{H}$, the sidewall was divided into 13 sections, whereby the sidewall in mining panel direction is called sidewall ' $a$ ' and the opposite sidewall is called ' $b$ '. In the first diagram, the results of the application of the rock mass classification systems in top drift $600 \mathrm{E}$, top drift $600 \mathrm{~F}$, drift $600 \mathrm{H}$ and at the pillar endings (documented separately) can be observed.

For the comparison of all rock mass classification results on a scale of $0-100 \%$, the Q-value was converted into an equivalent RMR value using the following relation after Bieniawski (1989):

$$
R M R_{Q}=9 \ln Q+44
$$


The following diagrams show the rock mass classification results based on geological features, i.e. excluding stress and blast induced fractures. Figure 7 shows the results of the application of the rock mass classification systems in the selected mining area.

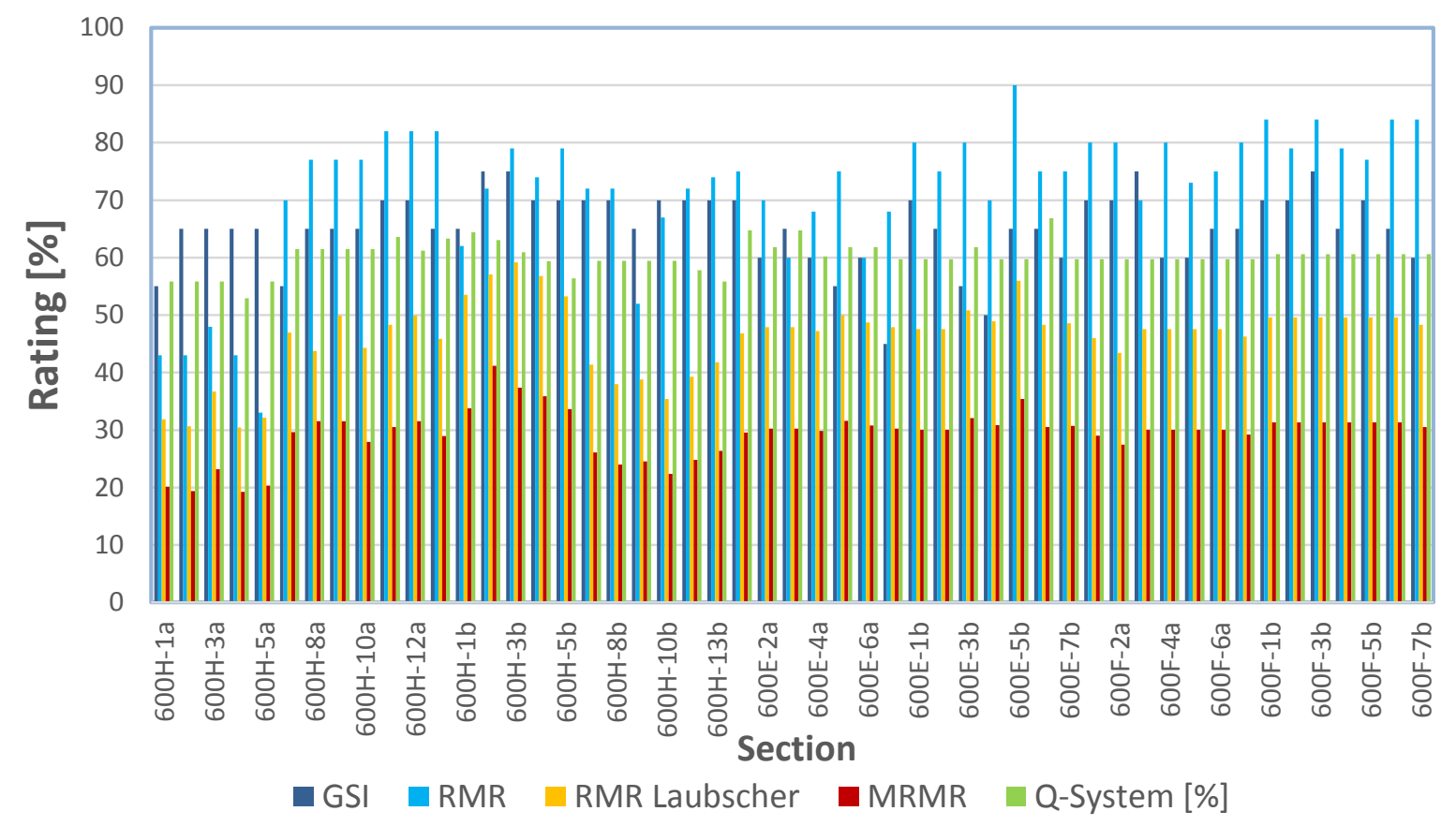

Figure 7 Overall results of the rock mass classification

The following results deal with the rock mass classification in top drift 600E. Figure 8 shows the results in sidewall ' $a$ ', Figure 9 shows the results in sidewall ' $b$ '. The comparison shows that in general there is no or little difference between the two sidewalls, except the RMR value after Bieniawski. These results do not tell anything about the determined rock mass strength, but show the results of the application of the presented rock mass classification systems in the investigated underground mine on a scale of $0-100 \%$. The evaluation of the rock mass conditions based on the rating can be obtained from Figure 10.

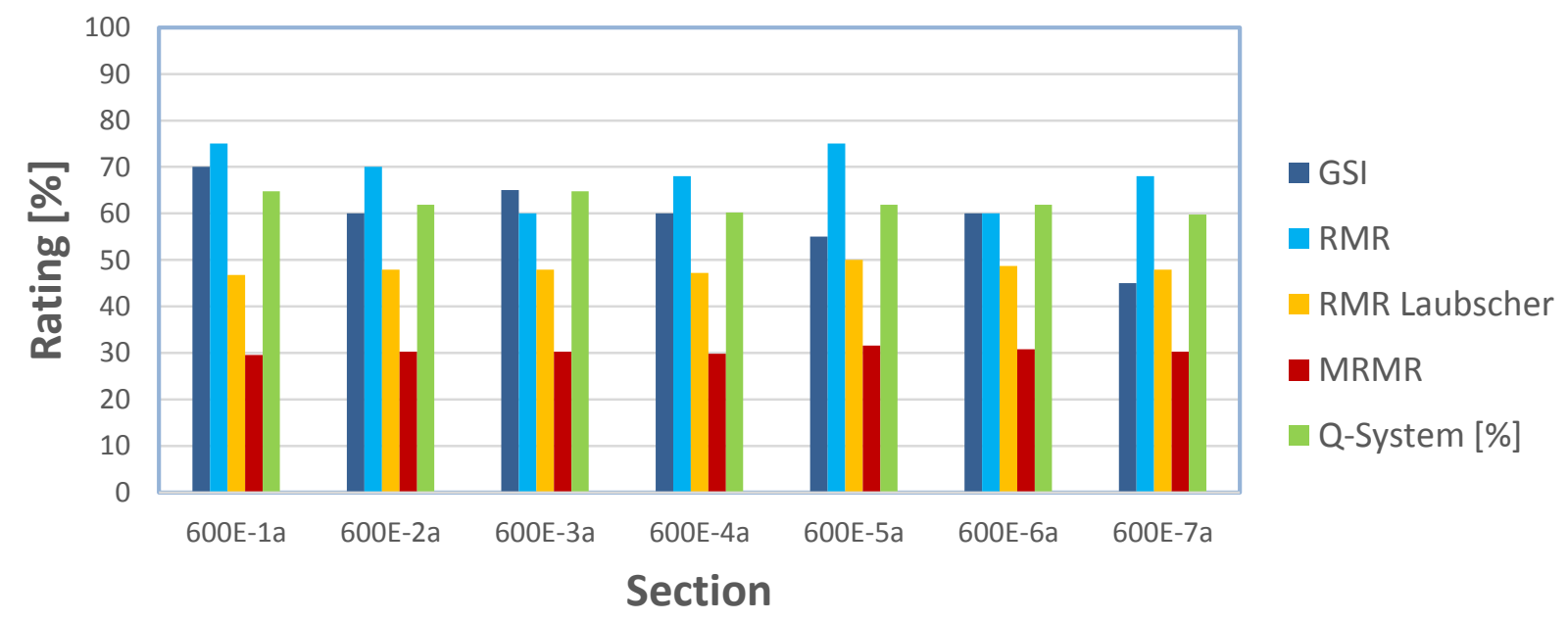

Figure 8 Results of rock mass classification in top drift 600E, sidewall 'a' 


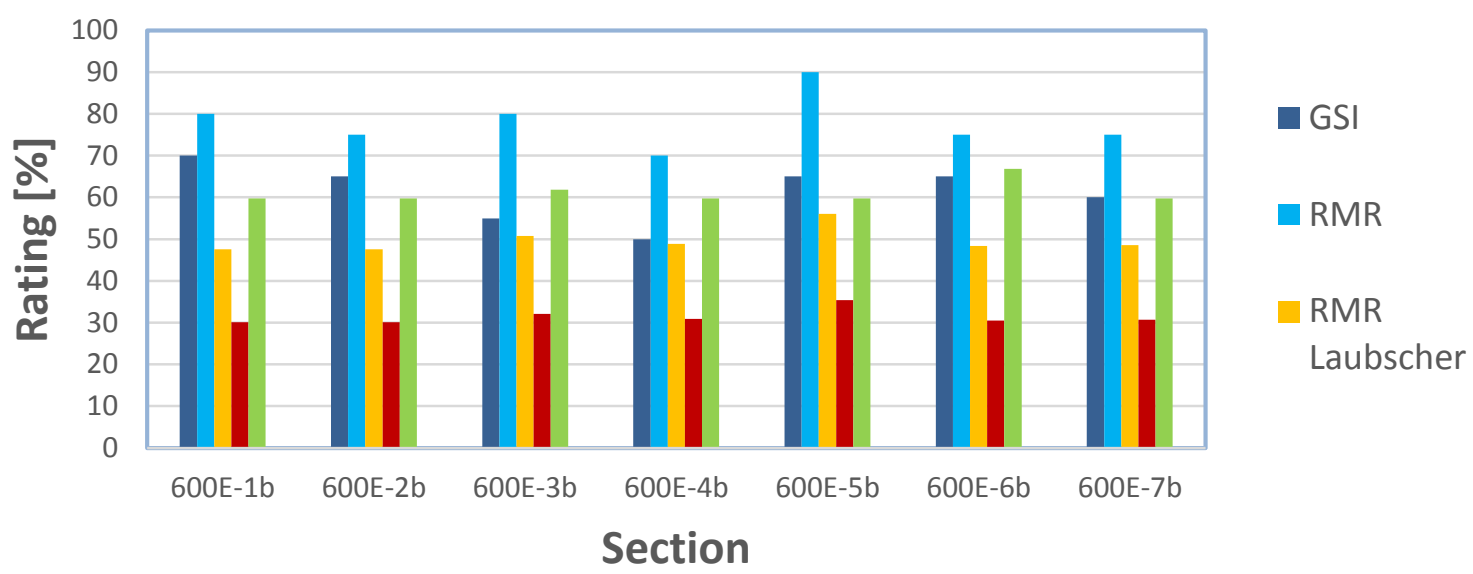

Figure 9 Results of rock mass classification in top drift $600 \mathrm{E}$, sidewall ' $b$ '

\subsection{Summary of rock mass classification results}

The investigation of rock mass conditions in drift $600 \mathrm{H}$ indicates no or only slight differences in the rock mass classification rating between the drift walls facing the extraction panels and those facing the unmined area. Rock mass conditions along the drift were found to be fairly constant. Significant differences were observed in the rating values of the different rock mass rating systems. Bieniawski's RMR ${ }_{89}$ rating system values consistently yielded the highest values followed by the GSI and $Q$ and Laubscher's RMR rating systems. Laubscher's MRMR rating values which are significantly lower cannot be compared directly as these include numerous adjustments for mining and rock stress conditions. Since the different rating systems use different weighting factors for the individual parameters and do not always use the same parameters or do not consider some of the parameters, the overall rating values cannot be compared directly. For this reason it is important to consider the different meanings of the diverse classification systems (Figure 10) explained by the authors.

\begin{tabular}{|c|c|c|c|c|c|c|c|c|c|c|c|}
\hline & & & & & & & & & & & Exceptionally good \\
\hline & & & & & & & & & & & Extremely good \\
\hline RMR & & & & & & & & & & & very good \\
\hline $\mathbf{Q}$ & & & & & & & & & & & good \\
\hline GSI* & & & & & & & & & & & fair \\
\hline MRMR & & & & & & & & & & & poor \\
\hline \multirow[t]{4}{*}{ RQD } & & & & & & & & & & & very poor \\
\hline & & & & & & & & & & & extremely poor \\
\hline & & & & & & & & & & & exceptionally poor \\
\hline & $0-10$ & $10-20$ & $20-30$ & $30-40$ & $40-50$ & $50-60$ & $60-70$ & $70-80$ & $80-90$ & $90-100$ & \\
\hline
\end{tabular}

*It should be noted that the GSI value was not intended by Hoek and Brown to be used as a rock mass rating value but rather as an input value into the general Hoek-Brown failure criterion which describes the effects of discontinuities and their properties on rock mass strength.

\section{Figure 10 Comparison of different rating systems and the according classification}

In the discussion of the application of rating systems for rock mass evaluation the issue of mining and stress induced fractures was raised. Figure 11 shows the differences in rating values if only geological fractures and discontinuities are considered are compared to those incorporating all visually observable features, i.e. geological and induced fractures. The differences observed are in general caused by the opening of fractures and the average distance between fractures. These points are only considered in the RMR and GSI rating systems but not in the MRMR and Q-systems. Figure 11 shows that in several sections of the drift the difference in rating can be as high as $30 \%$ as far as the RMR and GSI rating values are concerned. 


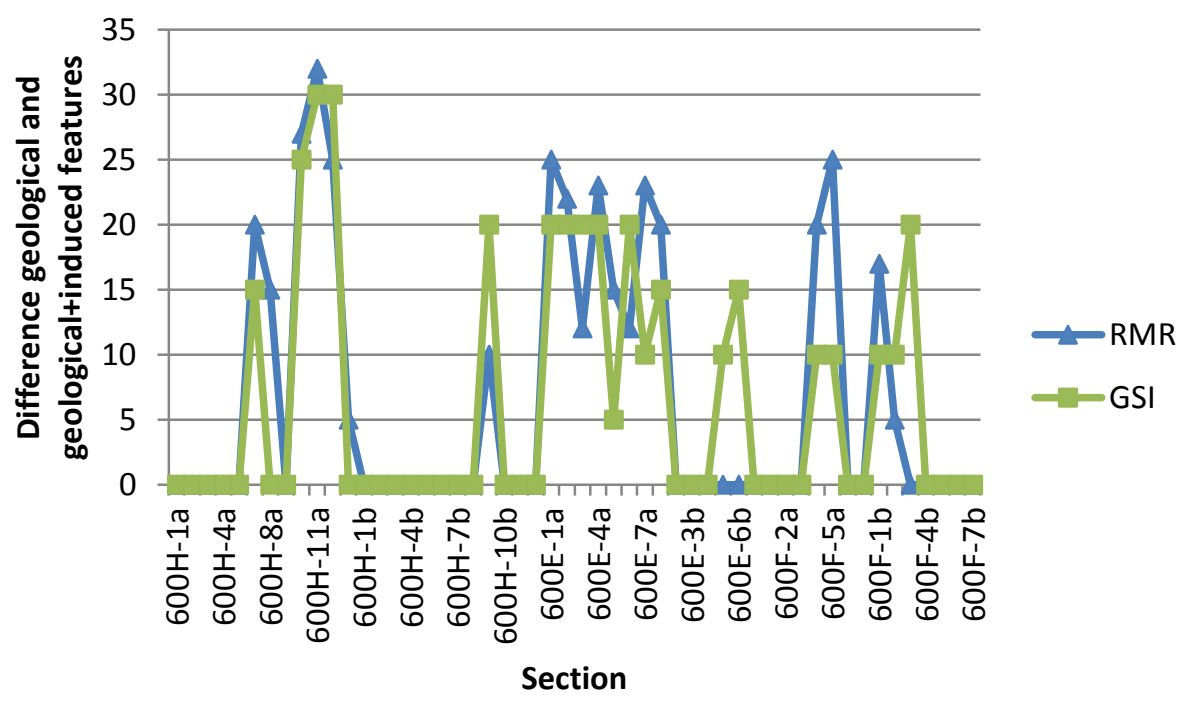

Figure 11 Difference in ratings between geological and geological \& induced fractures as input parameters into rock mass classification systems

\section{Assessment of rock mass strength}

Fracturing in a rock mass takes place when a combination of stress, strain, temperature and time exceeds a critical threshold. According to Edelbro (2003) three primary rock failure mechanisms can be distinguished in hard brittle rock conditions, namely tensile failure, spalling (extensional failure) and shear failure. One of the major challenges of underground mine design is the determination of the rock mass strength in order to design the openings in a way that is still safe but on the other hand allows the maximum possible extraction of ore. In general different approaches can be distinguished, namely the direct determination of the rock mass strength in situ, the derivation of the rock mass properties from rock sample testing in the laboratory, estimation through mathematical models and back-analysis of failures (Edelbro 2003). Rock mass classification systems are the basis of many empirical approaches to determine the rock mass strength. In the following, the most common empirical approaches to determine the rock mass strength based on results from rock mass classification systems are presented. For all approaches except the Hoek-Brown rock mass strength relationship, the same precondition can be applied: the calculated rock mass strength, $\sigma_{c m}$, is the unconfined compressive strength of the rock mass. Hoek et al. (2002) distinguish between the uniaxial compressive strength of the rock mass, $\sigma_{c m}$, and the global strength of the rock mass, $\sigma_{c m}{ }^{\prime}$, which considers the stress environment around underground excavations. For the design of such excavations and mine pillars Hoek et al. (2002) recommend the use of the global strength, $\sigma_{c m}{ }^{\prime}$, which can be calculated as follows:

$$
\sigma_{c m}{ }^{\prime}=\sigma_{c i} \frac{\left(m_{b}+4 s-a\left(m_{b}-8 s\right)\right)\left(\frac{m_{b}}{4}+s\right)^{a-1}}{2(1+a)(2+a)}
$$

Where $\sigma_{c i}$ is the compressive strength of the intact rock and $m_{b}, \mathrm{~s}$ and $a$ are the modified Hoek-Brown parameters which take into account the GSI rating of the rock mass.

In this paper only a selection of available equations for the determination of the rock mass strength is presented. The choice of the presented approaches mainly depended on the rock mass classification systems which were applied in the investigated underground mine as well as on the commonness of use of these methods. A description of the different rock mass strength equations was left out consciously as this would on the one hand go beyond the scope of this paper and on the other hand should not be in the focus of the work. The focus of this work lays in the application of the different systems in an underground mine and especially the difficulties that one is facing during application when the right input parameters have to be chosen. A detailed description of the methods is left out and can be looked up in the according literature (Ramamurthy 1985; Hoek et al. 2002; Trueman 1988; Laubscher 1990; Barton 2002). 


\subsection{Results for the rock mass strength based on the presented approaches}

Based on the rock mass classification which was conducted in the underground drifts, the rock mass strength was calculated using the presented approaches. In the following in Figure 12 the results of the rock mass strength calculation of all sections are presented. The results are respresented in descending order. As a result of the discussion in Section 2.2, an average RQD value without considering the first $2 \mathrm{~m}$ was taken into account for the calculations as well as an average UCS without the consideration of the first $2 \mathrm{~m}$. The rock mass strength values vary between 4 and $111 \mathrm{MPa}$. In Figure 12 the rock mass strength after Trueman (1988), Hoek et al. (2002) (uniaxial) and the mining adjusted rock mass strength after Laubscher (1990) are shown as dotted lines as they are not used for further interpretations and for the calculation of the average rock mass strength. The reasons for this will be explained in the following chapter.

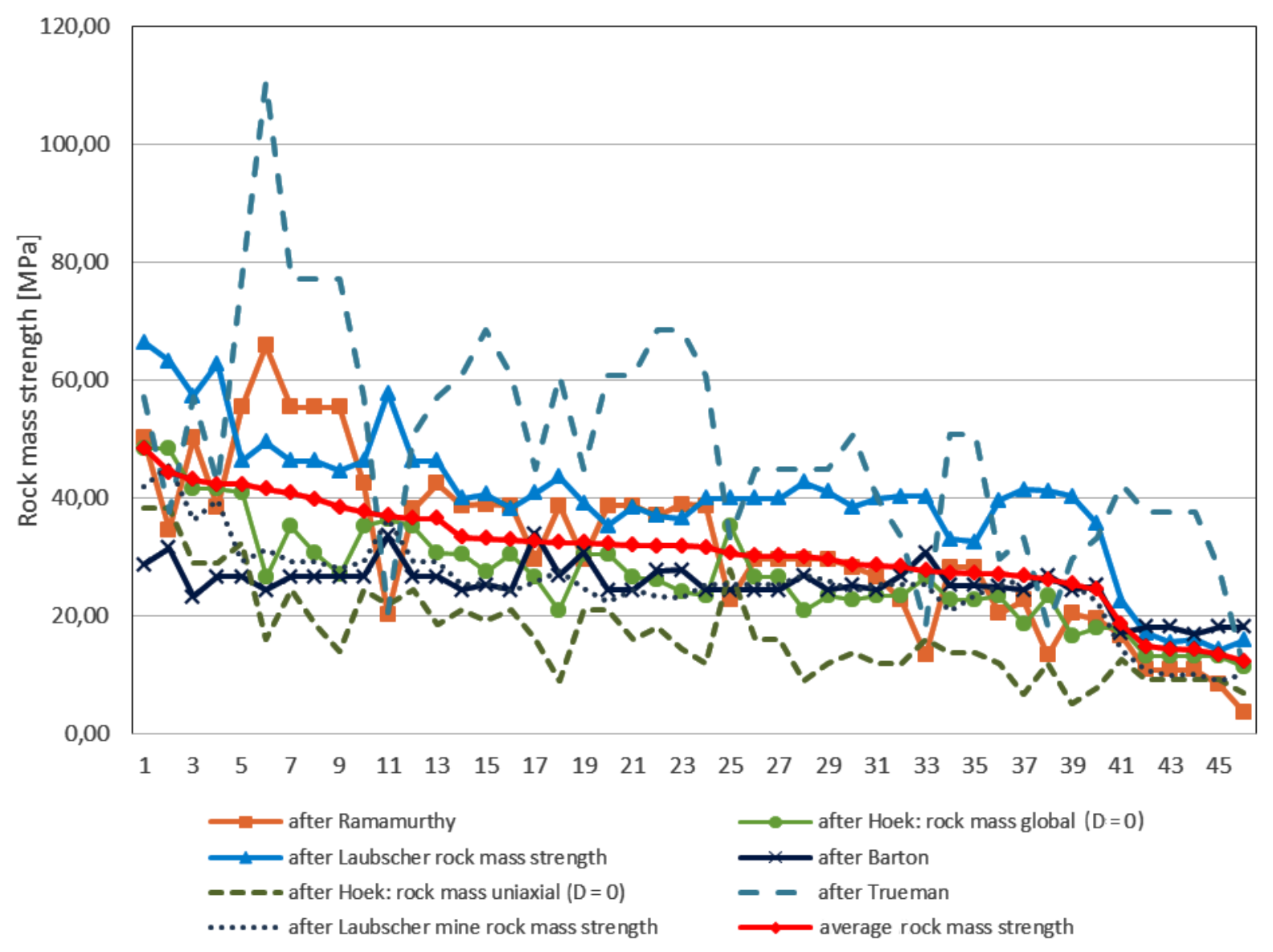

Figure 12 Overall rock mass strength results

\subsection{Discussion of the results}

Excluding the strength values after Trueman (1988) which are solely based on RMR and ignore intact rock strength the rock mass strength values fall in a band with a width corresponding to about $50 \%$ of the maximum strength value of a particular drift section. It should be noted that Zhang (2016), who compared different approaches for rock mass strength assessment made similar observations. Similarly Laubscher's design rock mass strength was excluded as well from the comparison as it contains a number of adjustments which are not part of the other assessments. The uniaxial rock mass strength after Hoek (2002) was excluded from the calculation of the average rock mass strength as well which will be explained later on. For these reasons the average of the rock mass strength value was calculated without considering Trueman, Hoek (uniaxial) and mining adjusted rock mass strength after Laubscher. It is noted that the rock mass strength values based on the empirical approach after Barton (2002), $\sigma_{\mathrm{cm}}$, and the 'global rock mass strength' after 
Hoek et al. (2002) compare reasonably well with the rock conditions in the mine drifts covered in this study and can therefore be used as a basis for further considerations.

As the rock mass strength determination is based on the ratings from rock mass classification systems, the results need to be examined critically as well. Five different approaches have been used to determine the rock mass strength based on different rock mass classification systems in order to determine the most reasonable rock mass strength value. When taking a look at rock mass strength values excluding the strength estimates after Trueman (1988), the uniaxial rock mass strength after Hoek (2002) and the mining adjusted rock mass strength after Laubscher (1990) variations in a percentage of 60\% larger and $70 \%$ smaller than the average value are obtained (Figure 12).

Cai et al. (2004) and Kaiser and Kim (2015) have commented on the difficulty in determining the strength of strong brittle rock masses. In particular they refer to the fact that in these rock masses failure of rock in the vicinity of excavations is caused by the formation of tensile cracks in the direction of maximum tangential stress in the excavation walls, i.e. rock spalling. These cracks initiate at a stress level of $0.4-0.5 \cdot \sigma_{c i}$ and later result in the formation of rock slabs in the excavation walls (Martin 1997; Brown 2008). This phenomenon of brittle rocks is not covered by the Hoek-Brown rock mass strength approach which is based on the rock mass shear failure mechanism similar to that of the Mohr-Coulomb failure criterion. According to Kaiser and Kim (2015) the Hoek-Brown strength criterion underestimates the strength of brittle rock masses in particular in situations of greater confinement such as found in squat pillar situations. Brown (2008) has acknowledged this and at the same time has warned against the non-critical application of the Hoek-Brown criterion. An examination of Figure 12 shows that the uniaxial rock mass strength according to Hoek-Brown yields very low strength values which are not supported by rock conditions in drive $600 \mathrm{H}$. This supports the recommendation by Hoek and Brown to use the global rock strength to describe rock conditions in underground mines. For this reason the Hoek-Brown uniaxial rock mass strength has been excluded from further considerations.

Apart from the large difference in rock mass strength values there is also the question which of the different approaches of strength assessment is the most realistic for the mine under investigation.

To address this issue it is necessary to examine the conditions in the stope- and development drives and their stress environments. All drives have a width of $6 \mathrm{~m}$ and a height of $5 \mathrm{~m}$ and have been developed by means of drilling and blasting. The roof of all drives is supported by a regular pattern of $3 \mathrm{~m}$ long mechanical rockbolts spaced 1-2 m apart.

Based on depth of mining primary vertical rock stress is about $25 \mathrm{MPa}$. Based on conditions in the mine tunnels the primary horizontal rock stress is of a similar magnitude. Numerical simulations of a mining layout similar to that shown in Figure 1 indicate average pillar stresses of about $40 \mathrm{MPa}$ and abutment stresses of $30 \mathrm{MPa}$. These stress values are equal to or slightly higher than the average rock mass strength values shown in Figure 12. Allowing for the stress concentrations around the mining excavations intense rock fracturing of stope drives and the mining drift $600 \mathrm{H}$ could be expected. As the borehole observations indicate the rock within a distance of two to three metres from the walls of the 5 by $6 \mathrm{~m}$ wide drives is fractured. The drives which have a regular rockbolt support pattern in the roof but no regular rockbolt support pattern in the walls are in relatively good conditions with the exception of the corners of the square drifts and a section in drift $600 \mathrm{H}$ in the vicinity of borehole $600 \mathrm{H} 9$ and $600 \mathrm{H} 10$ where massive rock slabs have developed in the unsupported sidewall facing the stoping area. Conditions in the stope drives are good to average with the exception of the intersections of the stope drive with the cross cuts. In this area grouted rope support is employed to stabilise the ends of the stope pillars.

The results show that there is a damaged zone in the immediate vicinity of the underground excavations. However, the rock mass strength was only calculated for the rock mass outside the damaged zone (Figure 14). As a further step under this project it is planned to determine strength parameters in the immediate vicinity of the excavation using rock mass quality based on the RQD values within the fractured zone as well as by using the disturbance factor D after Hoek et al. (2002) for back calculations. 


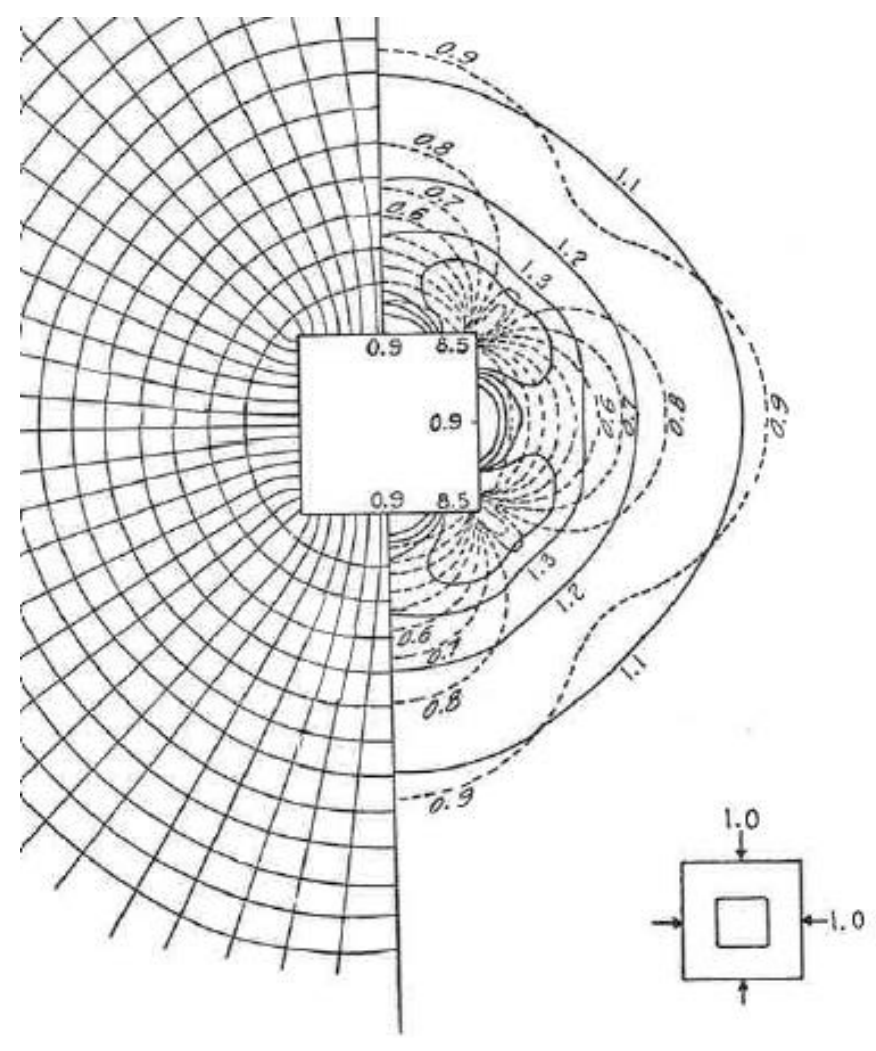

Figure 13 Principal stresses and stress trajectories around a square mine tunnel subjected to vertical and horizontal stresses of equal magnitude (Hoek \& Brown 1980)

In comparing the conditions of mine drifts in the experimental area with the strength values of the rock mass it needs to be born in mind that in contrast to circular tunnels the tangential stress acting in the mid-height or span of the tunnel is much lower than that of circular tunnels. According to Hoek and Brown (1980) the tangential stress in the case of horizontal to vertical stress ratio of 1 is only $0.9 \cdot \sigma_{1}$ instead of $2 \cdot \sigma_{1}$ (Figure 13). In the corners of the square tunnels rock stresses are much greater but highly confined small areas. Principal stresses at mid-height of the tunnel reach a maximum value of about $1.3 \sigma_{1}$ at a distance of about 0.5 of tunnel height.

The results of the drill core evaluations and rock mass strength estimations and observations of ground condition in the mine drifts covered by this investigation are supported by the stress situation around deep square mine tunnels. Stresses at the drift walls with the exception of the tight corners are about the same as the regional stress level, i.e. in the case of stope drives around $40 \mathrm{MPa}$ and development drive around $30 \mathrm{MPa}$. Uniaxial compressive strength of the rock mass falls in the range. The first two to three metres from the drift wall have a low to very low RQD value which is indicative of intense rock fracturing. At greater distances from the drift wall the maximum principle rock stresses decrease and the rock is more confined. This is reflected in the high to very high RQD values.

An alternative approach to rock strength assessment is the use of the concept of a 'rock wall condition factor' which was developed to assess the behaviour of deep gold mine tunnels. A survey of many tens of kilometres of gold mine tunnels showed that conditions of unsupported gold mine tunnels with square cross sections of 3 to $4 \mathrm{~m}$ showed that tunnel conditions deteriorated significantly when the maximum tangential stress in the tunnel walls exceeded a value of about $70 \%$ of uniaxial compressive strength the rock in which the tunnel is situated (Wiseman 1979). 


$$
R C F=\frac{\left(3 \sigma_{1}-\sigma_{3}\right)}{F * \sigma_{c i}}
$$

where:

$$
\begin{aligned}
\mathrm{RCF}= & \text { the so called 'rock wall condition factor'. } \\
\sigma_{1}, \sigma_{3}= & \text { the maximum and minimum principal stresses at the site of the tunnel or drift. The } \\
& \text { expression in brackets is a measure of the maximum tangential stress in the excavation } \\
& \text { wall. } \\
\sigma_{c i}= & \text { the intact rock strength. } \\
F \quad= & \text { a strength reduction factor which falls between } 0.5 \text { for heavily jointed rock and } 1 \text { for } \\
& \text { unjointed massive rock. }
\end{aligned}
$$

Using principal stress values of $30 \mathrm{MPa}$ and a value for $\mathrm{F}$ of 0.75 an intact rock strength value of $114 \mathrm{MPa}$ is obtained from Equation (3). This value is in good agreement with the average intact rock strength along development drive $600 \mathrm{H}$ which is about $100 \mathrm{MPa}$.

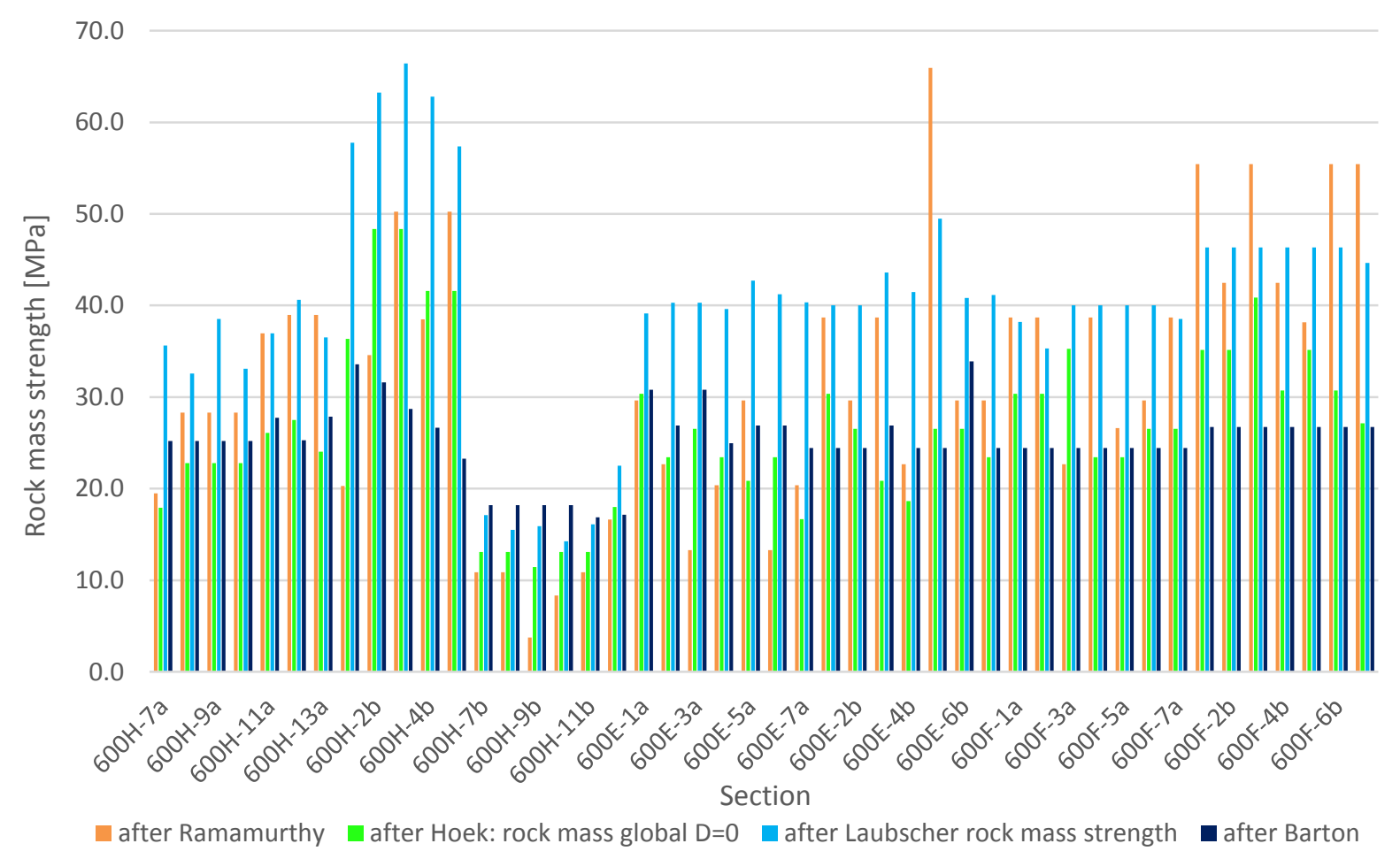

Figure 14 Rock mass strength values without results after Trueman (1988), Laubscher (1990) (mining adjusted) and Hoek (2002) uniaxial

\section{Conclusion}

The objective of this paper was to present the application of rock mass classification systems as a tool for rock mass strength determination. Different rock mass classification systems, namely the approaches after Bieniawski, Barton, Laubscher, and Hoek and Brown, were applied in a deep Austrian magnesite mine. From the application of these systems the following conclusions could be drawn.

The application of rock mass classification systems for rock mass strength determination can provide a reasonable estimate of rock mass conditions but faces a number of difficulties concerning application as well as the choice of input parameters.

The commonly used rock mass classification systems place an overriding importance on discontinuities, whereas the effect of rock strength is rated very low or is even neglected. 
The approaches which are mainly based on the visual observation of the excavation walls are influenced by the effects of blasting activities and stress changes. Every effort should be made to account for these effects in the final rock mass assessment.

Depending on the calculation method, a change in single parameters can have a major influence on the final strength result.

When the RQD value or the UCS of the rock is used as input parameter, the difficulty is which RQD or UCS to use (an average RQD over the total length of the borehole or an RQD/m borehole length). RQD and UCS values determined from drill core sections within the fracture zone around excavations should not be used for rock mass classification.

Regarding the underground investigations, no correlation between the RQD value and the UCS of the rock could be found.

The GSI mainly consists of the overall assessment of the rock structure which is difficult to perform in highly jointed brittle rock masses. The use of the concept of block size and block volume to determine GSI in deep mining situations is promising.

When making a comparison between the different rock mass classification systems, a relatively low rating using Laubscher's MRMR system is observed.

The problem in assessing the rock mass properties in deep mines is that the rock mass in the vicinity of mining excavations is affected by the excavation process and stress induced rock fracture. Separating in situ rock mass features from these effects is difficult. Objective and emphasis of rock mass classification should be to assess in situ rock mass properties and to account for mining related effects in a separate stage.

The Hoek-Brown uniaxial compressive strength estimate results in comparatively low strength estimates. Instead it is proposed to use the Hoek-Brown global strength estimate.

When dealing with rock mass strength estimates, a large number of relations based on the rock mass classification is available which can result in highly varying rock mass strength values. More research needs to be done to reliably and realistically determine rock mass strength properties.

Given the uncertainties concerning rock mass strength determination it is recommended to apply a number of methods to obtain an indication of uncertainty of strength values.

Considering the uncertainty of rock mass strength value a conservative approach to mine structure design is recommended.

Simple approaches such as the RCF can provide a meaningful first assessment of tunnel conditions in deep mines.

A systematic program of back analysis of behaviour of mine structures is recommended as it can in the long-term reduce the uncertainties concerning rock mass strength values.

\section{References}

Barton N 1990, 'Scale effects or sampling bias?', in A Pinto da Cunha (ed.), Proceedings of the First International Workshop on Scale Effects in Rock Masses, 7-8 June, Loen, Balkema, Rotterdam, pp. 31-59.

Barton, N 2002, 'Some new Q-value correlations to assist in site characterisation and tunnel design', International Journal of Rock Mechanics and Mining Sciences, vol. 39, no. 2, pp. 185-216.

Bieniawski, ZT 1989, Engineering Rock Mass Classifications, John Wiley \& Sons, New York, pp. 251.

Brady, BHG \& Brown, ET 2006, Rock Mechanics for Underground Mining, 3rd edn, Springer Science \& Business Media, Berlin.

Brown, ET 2008, 'Estimating the mechanical properties of rock masses', in Y Potvin, J Carter, A Dyskin \& R Jeffery (eds), Proceedings of the 1st Southern Hemisphere International Rock Mechanics Symposium, Australian Centre for Geomechanics, Perth, pp. 3-21.

Cai, M, Kaiser, PK, Uno, H, Tasaka, Y \& Minami, M 2004, 'Estimation of rock mass deformation modulus and strength of jointed hard rock masses using the GSI system', International Journal of Rock Mechanics and Mining Sciences, vol. 41, pp. 3-19.

Deere, DU \& Deere, DW 1988, 'The Rock Quality Designation (RQD) index in practice', in L Kirkaldie (ed.), Rock Classification Systems for Engineering Purposes, ASTM STP 984, ASTM International, West Conshohocken, pp. 91-101. 
Edelbro, C 2003, Rock Mass Strength: A Review, technical report, Luleå University of Technology, Luleå.

Hoek, E, Brown, ET, 1980, 'Empirical strength criterion for rock masses', Journal of the Geotechnical Engineering Division, ASCE 106 (GT9), pp. 1013-1035.

Hoek, E, Carranza-Torres, C \& Corkum, B 2002, 'Hoek-Brown failure criterion - 2002 edition', in R Hammah (ed.), Proceedings of the 5th North American Rock Mechanics Symposium and the 17th Tunnelling Association of Canada Conference, University of Toronto, Toronto, pp. 267-273.

Hoek, E, Carter, TG \& Diederichs, MS 2013, 'Quantification of the Geological Strength Index Chart', in LJ Pyrak-Nolte, A Chan, W Dershowitz, J Morris \& J Rostami (eds), Proceedings of the 47th US Rock Mechanics/Geomechanics Symposium, 23-26 June 2013, San Francisco, American Rock Mechanics Association, Alexandria, pp. 1757-1764.

Kaiser, PK \& Kim, B-H 2015, 'Characterization of strength of intact brittle rock considering confinement-dependent failure processes', Rock Mechanics and Rock Engineering, vol. 48, pp. 107-119.

Laubscher, DH 1990, 'A geomechanics classification system for the rating of rock mass in mine design', The Journal of the South African Institute of Mining and Metallurgy, vol. 90, no. 10, pp. 257-273.

Martin, CD, Kaiser, PK \& McCreath, DR 1999, 'Hoek-Brown parameters for predicting the depth of brittle failure around tunnels', Canadian Geotechnical Journal, vol. 36, pp. 136-151.

Marinos, P \& Hoek, E 2000, 'GSI - A geologically friendly tool for rock mass strength estimation', Proceedings of the GeoEng 2000 Conference, Melbourne, Technomic Publishers Co Inc, Lancaster, pp. 1422-1442.

Ramamurthy, T 1985, 'Stability of rock mass', Indian Geotechnical Journal, vol. 16, no. 1, pp. 1-75.

Salamon, MDG \& Munro, AH 1967, 'A study of the strength of coal pillars', The Journal of the South African Institute of Mining and Metallurgy, vol. 68, no. 2, pp. 55-67.

Siefert, M 2009, 'Verfahren zur qualitativen und quantitativen Beschreibung des Gebirges, 2 Teil: Quantitative Gebirgsbeschreibung', BHM Berg- und Hüttenmännische Monatshefte, vol. 154, no. 10, pp. 426-440.

Trueman, R 1988, An evaluation of strata support techniques in dual life gateroads, PhD thesis, Cardiff University, Cardiff.

Wiseman, N 1979, Factors affecting the design and condition of mine tunnels, Research Report No. 45/79, Chamber of Mines of South Africa, Pretoria, South Africa, pp. 22.

Zhang, L 2010, 'Estimating the Strength of Jointed Rock Masses', Rock Mechanics and Rock Engineering, vol. 43, pp. $391-402$.

Zhang, L 2016, 'Determination and applications of rock quality designation (RQD)', Journal of Rock Mechanics and Geotechnical Engineering, vol. 8, pp. 389-397. 
